\title{
The Application of the Process-Based Writing Approach in Composing an Argumentative Essay: A Case Study of a Suburban Secondary School of Mukah District in Sarawak
}

\author{
Stephanie Jee, Azlina Aziz \\ Faculty of Education, Universiti Kebangsaan Malaysia, Bangi, Malaysia \\ Email: step1602@yahoo.com
}

How to cite this paper: Jee, S., \& Aziz, A. (2021). The Application of the Process-Based Writing Approach in Composing an Argumentative Essay: A Case Study of a Suburban Secondary School of Mukah District in Sarawak. Creative Education, 12, 880-896. https://doi.org/10.4236/ce.2021.124064

Received: March 20, 2021

Accepted: April 25, 2021

Published: April 28, 2021

Copyright $\odot 2021$ by author(s) and Scientific Research Publishing Inc. This work is licensed under the Creative Commons Attribution International License (CC BY 4.0).

http://creativecommons.org/licenses/by/4.0/

\begin{abstract}
The Action Research purported to explore the use of process based writing approach in enhancing the form six learners' writing skills in a self-directed and motivating way. This research was conducted in a suburban secondary school of Mukah district in Sarawak. Twenty-three of Upper six learners with average to below average language proficiency were selected as the research participants. Two data collection instruments which were the pre and posts test were analysed to obtain research findings. Findings from pre and post tests revealed a significant result indicating a slight improvement with a mean score increment of $4.8 \%$. These results proved that the process based approach had successfully assisted the learners in writing an argumentative essay.
\end{abstract}

\section{Keywords}

Process-Based Approach, Argumentative, Form Six Learners, Writing, MUET (Malaysia University English Test)

\section{Introduction}

Writing is one of the important skills in learning English. It helps the learners to practice and transfer their existing knowledge into written form. According to Klimova (2012), writing is essential as it helps the writer to express his personality, develop thinking skills, make logical and persuasive arguments, and foster communication. Writing is crucial in learning the second language since its acquisition includes other skills such as listening, reading, and speaking as well, 
which at the same time involves metacognitive skills. In writing, learners need to have a clear objective so that they can plan and think over its layout and structure of content. Therefore, in the beginning, second language learners should play with their creativity and write freely because one can produce a good product if they enjoy doing it. Jones (2015) discovered that the nature of the writing activity, the process, and the things that encourage the learner to write is influenced by factors such as their audience involvement as this will determine their behaviour towards writing.

Hence, this study aims to use a process-based writing approach to encourage and enhance learners' writing skills to help them score well in their MUET. This chapter seeks to introduce the background of the study, the problems that affect their learning process, and to derive the purpose of the study based on the problem statements. This study is conducted in the form of Action Research. It also seeks to underline the significance of the study towards the teachers, learners, and 21st-century learning methods. At the end of this chapter, the limitation of the study and the operational definitions are stated in detail concerning this research.

\subsection{Problem Statement}

The problem arises when about there are $40 \%$ of the students in the class did not score well in their writing paper especially question 2 which carries $60 \%$ of the marks for writing paper. Most of the students were band 1 and 2 scorer and the marks remain unchanged in trial 2. This is due to their low proficiency in English and they face difficulties in transforming their ideas into written form. Thus, this situation shows that the teacher needs a different approach to teaching; a process-based writing approach, which suits the learner's learning pattern. Writing skills are an essential component of literacy where students need to be good at writing as part of showing their proficiency in using the language accurately. Effective writing skills are needed for students to be academically successful.

This situation, however, does not happen at the suburban schools but it happens at the urban schools, too. MUET syllabus was made according to the Common European Framework Reference for Languages (CEFR) to make sure that it is on par with other international English Proficiency Tests. Thus, the government took an initiative by stressing the importance of MUET among the learners especially the Pre-university learners. Since 2014, the learners who wish to apply to public universities need MUET. The government also set a minimum MUET band requirement upon entering and graduating depending on their chosen courses (New Straits Time, 2016). Writing paper could be difficult for the less proficient learners and lack of general knowledge which always happened among the suburban school second language learners. Learners tend to merely list the points without relevant elaboration as they can't depend solely on their previous knowledge in writing the essay but they also need to read to gain more 
general knowledge. Apart from that, the learners tend to have difficulty in understanding the requirements of the essay question well. According to Mawarni (2020), "the tendency of not to fulfil the requirements of the essay cause them to go off tangent when they write the essay which cost them to lose some of the marks." This statement can be supported by the analysis done by the Majlis Peperiksaan Malaysia (2018). MUET Session 3/2018 recorded 63.18\% of the candidates managed to score band 3 for their writing paper (Majlis Peperiksaan Malaysia 2018). This is a worrying situation because, according to the analysis provided by Majlis Peperiksaan Malaysia (2018), the candidates were not able to provide good answers and were unable to elaborate on their ideas. Hence, teachers should try on a different approach to help learners in the future to score in MUET especially on writing paper.

\subsection{Purpose of Study}

This research intends to use a process-based writing approach to enhance the form six learners' writing skills so that they can score better for writing papers in MUET.

\subsubsection{Research Objective}

Based on the purpose of the study that is to use a process based approach to enhance the form six learners' writing skills, the objectives of the research are as follows:

1) To reflect on the problems during writing class.

2) To assess learners' competency level in writing before and after implementing the cooperative learning in class.

3) To evaluate learners' writing skills after using the process-based writing approach.

4) To reflect and recommend the next action after the first cycle of implementing process-based writing approach.

\subsubsection{Research Questions}

Considering the research objectives of this research, the research questions are:

1) What are the learners' levels of competency in writing before and after the implementation of process-based writing approach?

2) What are the results of the evaluation of writing skills after implementing a process-based writing approach?

\subsection{Limitation of Study}

The limitation in a study is important because it develops a strong understanding of the context within a research to identify the scope of credibility and reliability of the research. It also determines the direction of the research as it will conclude and round off an outcome (Forero et al., 2019). In this research, the limitation of the study can be categorized into three main aspects, which are the context or locality, the participants involved, and the use of a new approach in 
learning and teaching.

In terms of context or locality, this research will be conducted in a suburban school where more than half of the form six learners are Melanau within the district of Mukah, Sarawak. The community in this school mainly speaks in the Melanau language and the community from this area is from average to low socioeconomic background. Thirty form 6 learners who scored less than 25 marks in their question 2 based on their trial examinations are the participants in this research. For the data collection, the scope of the items will only control the aspect of the learners writing skills. Statements and questions that to be included in the data collection instruments will target specifically on learners writing skills before and after the implementation of process-based writing approach and their opinions towards the new teaching and learning approach

\section{Writing from the Perspective of the Form Six Learners}

As asserted by Siddique et al. (2017), learning cannot take place especially when it involves writing skills because the learners are not following any learning theory for the instruction of any subject especially in the field of language learning. Learners are so used to the traditional method of learning and they are more comfortable to rely on their teachers to complete their writing tasks. Traditional methods involve teaching and spoon-feeding the learners especially the low proficiency learners. In this case, learners are introduced to a new approach; a process-based writing approach where the teacher acts as a facilitator and the learning process are more student-centred. Consequently, learners learn to be more independent and confident to complete the task given without relying on the teacher. Additionally, a process-based writing approach will help the students to enhance their communicative skills as it also involves presentation and discussion with other people. Indirectly, learners can improve their speaking skills as well. With such a positive outcome, the students will be able to expand their ideas and transform it into written form, which will help them to improve their score in writing paper.

\subsection{Writing as a Process vs. Product}

Process writing is an approach used by teachers to produce good writing among learners. This approach allows the teacher and the learners to go through a process to produce a text according to the topic given. During this process, the learners are given a chance to think about what to write, to build a draft, to revise, edit, and finally received feedback on their work before they produce the final product. This process provides extra time for the learners and allows them to produce the best ideas in writing.

As mentioned earlier, the process involves a few stages before the learners can produce a good final product. The first stage is the pre-writing stage. During this stage, the learners are required to create ideas and plans for their writing. This stage includes the process of brainstorming ideas, planning their writing, orga- 
nizing and lastly, selecting the suitable ideas. The learners are encouraged to work collaboratively by using techniques such as creating mind maps when discussing. The next stage is the writing stage. In this stage, the learners have to write the first draft of their texts. Composing the text can be done individually or in a group, depending on their proficiency level. At this stage, the accuracy of language, vocabulary, and punctuation is not required as this is only their first draft.

The third stage in process-based writing is revising the draft created. In this stage, the learners have the chance to revise their texts and reorganize the ideas, add, change or remove the unnecessary sentences to make sure their ideas are well-presented in the texts. Feedback from the teachers is also needed so that they can improve their writing stage until it fulfills the requirement of the question given. If there are any changes, they will have to go back to the writing stage to produce another draft. Feedback is an essential stage because it helps the learners to produce another draft that has better quality. Editing will be the last stage during the process-based writing. This is the stage where the learners can get their peers to proofread their draft, help to check their accuracy of the language, punctuation, and spelling. Indirectly, the learners will learn from the mistakes made by their peers.

Another approach that the teachers can consider to use to help the learners enhance their writing skills is the product writing approach. Unlike the process-based writing approach, it is an approach that focuses on the final production. Product writing approach consists of 3 stages; model texts, controlled practice, and organizing ideas. The first stage is a stage where the learners are exposed to the model texts of the genre that they are going to produce. They need to analyse the main features of the specific texts. Hence, this is different from the process-based writing approach which encourages the learners to create and brainstorming. The next stage in the product writing approach is the controlled practice. This stage is contrasting from the writing stage in process-based writing as the controlled practice stage requires the learners to practice on exercises such as the gap-fill activities, true or false, finding the mistakes in a text, and so on. The logic behind this stage is to instill the learners' confidence level so that they can produce their texts. The last stage is the learners have to organize the ideas. This is the phase where the learners generate the ideas and take notes on what they would like to include in the text and language that might be useful for them to produce their work.

Therefore, based on the learners' proficiency level and the suitable approach to help to enhance the learners' writing skills, it is preferable to use a process-based writing approach than a product writing approach. A process-based writing approach fosters creativity as it needs the learners' previous knowledge and start thinking about a text based on the ideas that they come up with. Unlike the product writing approach, it helps the learners to develop analytical skills. Analytical skills are indeed useful skills that anyone should have. However, analyzing 
the features is not an easy task especially for the low proficiency learners. Another reason that influenced decision-making is the process-based writing approach encourages peer learning. Peer teachers use their understanding of their learning to teach others. They feel more comfortable and open when interacting with their peers as they share the same discourse which allows them to understand better.

\subsection{Common Genre in MUET Writing Task: Argumentative Essay}

Argumentative essay is a genre where the students are require to study about a topic and gather information, produce and analyse facts which eventually they have to build a concise position on the subject. It is one that deals with the viewpoint of the narrator, who then has to use the same to make it convincing to a person with opposing views. Argumentative essays help you improve critical thought. Another advantage is to learn how you can talk on the subject and show their expertise in written form. It is a great way to expose the learner to the outside world and at the same time improve their English. One of the possible appeals for the essay is when the teachers at both levels play their part in linking the classroom with outside thoughts, problems and events (Schneer, 2014). Hence, that is why argumentative writing is commonly taught in academic writing textbook books for the learners and how closely it connects with the real world contexts.

\subsection{Cooperative Learning (Process-Based Writing Approach)}

Cooperative learning involves students by breaking them into small groups with the aim that they can discover a new concept together and help each other in learning. Cooperative learning is different from blended learning as cooperative learning. Blended learning involves technologies and a face to face teaching whereas cooperative learning requires students to collaborate and learn together. The teacher only works as a facilitator to guide them throughout the learning process. According to Johnson and Johnson (2020), the individuals that can survive are usually those who are best enabled to do so by their group. In a group, students can share their knowledge and decide ideas that are suitable according to the task to fulfil the task requirement. As asserted by Johnson \& Johnson (2020) also, within cooperative situations, individuals seek outcomes that are beneficial to themselves and their group members. Thus, cooperative learning is used as an instructional to maximize their learning.

\subsection{Challenges in Teaching and Learning English}

An English teacher faces challenges to teach the language in written form. There are many factors that contribute to the challenges faced by teachers of the English language. Sheeba (2018) mentioned four main challenges that students face in writing classes; lack of vocabulary, lack of grammatical knowledge, lack of 
motivation, and the learning environment. However, a teacher too has challenges in teaching students writing; motivation, use of technology, classroom management, and also different learning styles of the students. Vocabulary, according to Sheeba (2018) is the most important aspect of writing as it is the basic component of successful writing skills. Lack of vocabulary will become a crucial problem for both the teacher and student during a class activity. As for the grammar aspect, it is helpful for effective language skills. In writing, grammar determines the built up of a paragraph and how ideas could be understood. Students usually lack motivation as they behave in a negative way towards the subject matter, being the English language. This behavior can lessen a student's determination and effort in their writing skills. The environment too plays an important role in the learning process. Sheeba (2018) found that students in remote areas are not really supported by their surroundings being their parents and teachers as they view the English language as "less important for their children".

The lack of usage of the English language and the constant neglect of the language generally in schools, specifically those in remote or rural areas affects students' proficiency which leads to the shortage of application of the language in classes.

\section{Methodology}

The purpose of this study is to investigate the use of process-based writing approach in enhancing the Form six learners' writing skills. Process-based writing approach is used and study by referring to several past studies in relation to the implementation of the approach. Apart from that, this chapter also aims to introduce the research design, research participants, research instruments and also the data analysis techniques. Lastly, by the end of this chapter, the data collection procedures, the implementation of validity and reliability analysis and ethical consideration are also discussed based on this study

\subsection{Research Design}

This research is conducted using action research method. Action research is a process in which participants examine their own educational practice systematically and carefully, using the technique of research. In addition, action research also specifically refers to a disciplined inquiry done by the teacher with the intent that the research will inform and change his or her practices in future. The teacher, number of learners and writing approach are the same for the whole process. The effectiveness of this approach that is used in assisting learners in writing were measured based on their marks in writing assessment by the end of the cycle.

\subsection{Methodology Concerns}

Methodological concerns are used for the researcher to conduct a study which needs to be taken into account before conducting a study. In this case, three 
elements that will be highlighted in detail are population and sample of research, research instruments and also data analysis technique.

\subsubsection{Research Participants}

There are six classes of Upper Six in SMK Three Rivers, a suburban school in Mukah, Sarawak. By implementing non-probability sampling, one of the classes, which is the Upper $6 \mathrm{D} 2$ is selected to participate in this action research the learners in this class scored 5 - 40 marks for question 2 of the writing paper during trial exams. There are a total of twenty-three learners in the class and this small sample size is effective to monitor the implementation of process-based writing approach. The learners in the class consist of low to average language proficiency. Their level of proficiency is determined by their performance recorded in MUET trial exams throughout the year 2019 and 2020.

\subsubsection{Research Instruments}

Research instrument is a tool used to collect, measure and analyses the data that are related to the study. Research instruments can be questionnaires, surveys, tests and scales. For this research, tests are the tools used to collect the data.

At the early of this research implementation, the pre-test will be conducted. This step is crucial in order to collect and analyses the Upper Six learners' ability in producing an essay. The pre-test will consist of one argumentative essay and they are required to write an essay not less than 350 words.

For post-test, it will be conducted to gather and examine the Upper 6 writing skills after the implementation of the process-based approach. The post-test contains one argumentative writing question adapted from session 32017 MUET writing paper.

\subsubsection{Data Analysis}

Analysis of the data from the questionnaire and pre-test and post-test involves arrangement and analysis using the SPSS software. Then, the data is interpreted to answer the three research questions and to affirm the predicted outcomes. Limitations to process-based writing approach can also be explored, as well as limitations to this conducted research that impede effective interpretation of the results. The data and findings would be followed with recommendations for the improvement of process-based writing approach, and also suggestions for more reliable and valid related studies in the future.

\subsection{Data Collection Procedure}

First of all, the researcher observed the class of Upper Six learners for one month. Learners' proficiency, their interest in English and background were taken into account during the observation process. The researcher conducted a placement test to find out the standard of English among the learners. The test consists of 1 argumentative essay. The time allocated is 50 minutes. After that, papers are marked by the researcher and two experienced teachers. From the 
result, it will determine the students' proficiency level in second language and the factors that causes them not to be able to write a good essay.

The participants will undergo one cycle which will be conducted for 2 months. During this cycle, process-based writing approach is introduced to the learners. Learners will have to work in groups, present their ideas to the class and give feedback before the teacher give feedback on the ideas. This stage involves not only their speaking and writing skills, but it also involves critical thinking. The results of this cycle (post-test) will be used and compare with the pre-test result which will determine the effectiveness of the process-based writing approach.

After the observing stage is the final step before initiating another cycle of action research. In this stage, collecting data and analyzing the data are essential in order to answer the research questions previously. Based on the result obtained, reflections and evaluation will be done and any point for improvement and amendments will be noted for the next cycle to commence.

Overall, based on the cyclical process of an action research, the flow of this research has been formulated into stages as shown below:

Stage 1: Identifying Problem

- Initial data collection and analysis will be carried out to identify learners' problem in writing.

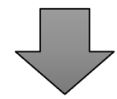

Stage 2: Planning Action

- Process-based writing approach will be applied to enhance learners' writing skills.

- Suitable data collection (pre-test, post-test) will be developed to gather evidence on participants' suitability with the approach.

Stage 3: Implementing Action

- Process-based writing approach was applied during the writing lesson on selected learners to measure its effectiveness.

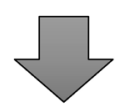

\section{Stage 4: Observing}

Observation process took place to monitor the implementation of process-based writing approach.

- Results were recorded for reflective phase using data collection methods (pre-test, post-test)

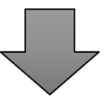

Stage 5: Reflecting and Evaluating

Results from observation phase were analysed and reflective and evaluative process was carried out.

- Any improvements and amendments were noted for the next cycle to commence. 


\subsection{Validity and Reliability}

Reliability and validity are concepts used to evaluate the quality of the research. Reliability is about the consistency of a measure where the results can be reproduced when the research is repeated under the same conditions. Validity is about the accuracy of a measure to the extent that it is really measure on what they are supposed to measure, it requires the researcher to check how well the results correspond to the theories and other measures of the same concept.

\section{Face and Content Validity of Pre-Test and Post-Test}

The pre-test and post-test were created by adapting the previous MUET exam paper which then used as the main reference to develop the test items. The marking criteria prepared by the Majlis Peperiksaan Malaysia (MPM) are used for marking later on. Hence, the content validity is achieved as the tests are set to measure the learners' writing skills.

For the aspect of face validity, the pre-test and post-test were analysed by an expert teacher to determine the feasibility and practicality of the writing question. The expert teacher is the school MUET Coordinator in SMK Three Rivers, Mukah, Sarawak. With the expertise and experience from the expert teacher, the pre-test and post-test were able to achieve face validity.

\subsection{Ethical Consideration}

The researcher will first decide on the title and topic of research in relation to the researcher's interest. The researcher will then proceed with the application of permission from the faculty to conduct and proceed with the selected research. The researcher can proceed with the selection of research participants once the permission is granted. Upper $6 \mathrm{D} 2$ learners' are selected prior to the data collection procedures. Consequently, with the targeted participants in hand, the researcher will ascertain the research venue and applies for school permission before conducting the study. After that, the researcher began with the implementation of the research.

In order to follow the standard operation procedure, the researcher will also be required to brief and inform the participants of the reasons that they are involved in the research, the purpose, aim and objectives of the research.

\section{Findings, Discussion and Implication}

The research methodology from the last chapter examined the design of the research, the instruments, participants, data analysis methods, procedures for the collection of data, analysis of validity and reliability and ethical factors. This chapter addressed in depth the conclusions of the study, the discussions and the results of the findings.

The data collected from the study were analysed using statistical analysis. The results of the statistical analysis will be presented in order to prove the hypothesis and answer the research questions. The results will be discussed in detail to determine whether the research hypothesis can be accepted or not. 


\subsection{Findings, Discussion and Implication}

Action Research is the superordinate term for a group of approaches to study and at the same time consistently examines the social condition and facilitates political reform and collaborative engagement (Dick, 2015). Action research model begins with "problem identification" process followed by "planning", "implementation" action, "observing" and finally with the "reflecting and evaluating" process. Each of the processes requires thorough planning and evaluation before moving onwards to another subsequent process. Action research does not imply the intervention strategies that will show immediate and clear-cut improvements in practice; but it does mean that the purpose and forward movement of the action research process is consistently focused on enhancing practical conditions within the social situation.

During the first step of the data collection procedures, the pre-test is in order to identify and prove that the issue on the learners writing skills especially when writing an argumentative essay. With the issue identified, this will facilitate the "planning for action" stage which leads to the used of process-based learning strategy in writing class.

\subsubsection{Findings, Discussions and Implication: "Identifying Problem" Process}

For the first part of the Action Research cycle, the "identifying problem" process aims to collect initial data in order to identify focus or problems in the teaching and learning practices that require improvement (Dick, 2015; Laidlaw, 1992; Lewin, 1946). For this research, it was observed that the participants were facing problem in elaborating their ideas in writing. Hence, this stage was purported to collect initial data in identifying participants; problem in the teaching and learning of writing skills. For this stage, twenty-three participants of the Upper six learners were given a task to discuss and write an argumentative essay based on the topic given for three periods of MUET lesson. Throughout the lesson, the learners were prompted with several questions after they presented their ideas to the class. After the teaching and learning sessions, the pre-test was administered on the following day for 3 periods of the lesson to identify the learners' ability to compose an argumentative essay. The checking of the pre-test was conducted together with the expert teacher to obtain bias-free results for the participants of this research. After checking, the learners' results were tabulated statistically in the form of mean score and percentages through the use of SPSS version 26. Table 1 shows the percentages and mean scores of the pretest that were collected.

\subsubsection{Findings, Discussion and Implication: "Implementing Action" Process}

The next "implementing policy" process directed at the administration of an action plan or initiative developed by study participants (Dick, 2015; Laidlaw, 1992; Lewin, 1946). A total of twenty three Upper 6D2 learners were chosen as study participants. For the purpose of this action study, specific sample size was 
chosen to efficiently track the administration of process-based writing, which uses $5 \mathrm{~W} 1 \mathrm{H}$ questions to ensure that each process provides output to the next process, often aiming towards the same end. In terms of language proficiency, based on the performance of the English language reported during Form five, the learners in the class consisted of "Average Language Proficiency" to "Low Language Proficiency" The course of action took place for one month with a few exercises using the template prepared by the researcher. The first part of the execution of the action was used for the first through the third period of the MUET lesson with the $5 \mathrm{~W} 1 \mathrm{H}$ template administered individually.

Table 1. Result of the Pre Test and the learners' Band.

\begin{tabular}{|c|c|c|}
\hline \multirow{2}{*}{ Pseudonym } & \multicolumn{2}{|c|}{ Result } \\
\hline & Pre-Test & Grade (Band) \\
\hline Allysha & 13 & 1 \\
\hline Amalyn & 26 & 2 \\
\hline Brenda & 5 & 1 \\
\hline Calvin & 24 & 2 \\
\hline Caroline & 26 & 2 \\
\hline Dayangku & 5 & 1 \\
\hline Gwendolyne & 39 & 4 \\
\hline Hafizul & 23 & 2 \\
\hline Ivy & 20 & 1 \\
\hline Joshua & 20 & 1 \\
\hline Maxwell & 12 & 1 \\
\hline Myronne & 21 & 2 \\
\hline Aina & 22 & 2 \\
\hline Asyraaf & 23 & 2 \\
\hline Nur'ain & 23 & 2 \\
\hline Nurazwarhani & 23 & 2 \\
\hline Azreen & 10 & 1 \\
\hline Farhana & 15 & 1 \\
\hline Masdiana & 17 & 1 \\
\hline Slyvestine & 30 & 3 \\
\hline Suwandi & 24 & 2 \\
\hline Victor & 23 & 2 \\
\hline Wilnie & 16 & 1 \\
\hline Mean Score & 20.0 & 1 \\
\hline
\end{tabular}


The $5 \mathrm{~W} 1 \mathrm{H}$ question template was given to each learner as a tool during their writing lessons. After completing the template based on the issue, discussions were held as the learners shared their work with the class and gave input on the work of their peers. Before starting on the activity, participants were instructed on the procedures to fill out the template.

After completing the template, the instructor gave guidance and a discussion was conducted to ensure that each planning was connected to each other. At this point, the presentation of each individual was important, since it was necessary to explain to the class and demonstrate the relation of their ideas and their elaboration. Ideas must be connected in order to prevent their end result being out of the question.

At the final stage of the action, during the following week at the fourth, fifth and sixth periods of the MUET classes, the participants were given a post-test where they required to compose an argumentative essay. As this section reflects only on the execution of the action, the findings of the post-test were addressed in depth during the final phase of the Action Research Period.

From the observations and discussions at this stage, it was observed that the implementation of a process based writing strategy enabled participants to understand and participate in an enjoyable and substantive way. While this stage focused primarily on the mechanism of implementing the action, the next stage of "observation" looked at the specifics of the participants' behavioral experiences when using the $5 \mathrm{~W} 1 \mathrm{H}$ template.

\subsubsection{Findings, Discussion and Implication: "Reflecting and Evaluating" Process}

The final stage of the cycle was the "reflection and evaluation" process, which sought to assess and determine the influence and effect of action and to report on the testing process based on the data obtained (Dick, 2015; Laidlaw in 1992; Lewin in 1946). At this point, the key feature was to review and evaluate the post-test and to focus on the overall effect and result of the process-based writing approach using the $5 \mathrm{~W} 1 \mathrm{H}$ template. Following a process-based writing approach, the post-test was conducted to assess the suitability of the learners to adapt the new method in writing. Similar to pre-tests, post-tests have been checked by a researcher with the help of an experienced teacher. After testing and updating, the outcomes of the learners were statistically tabulated in SPSS version 26 to obtain the mean score and percentages. Post-test results were then compared with pre-test results to demonstrate the efficacy of the process-based writing strategy, with the goal of improving learners' writing skills, particularly when narrating an argumentative essay. Table 2 indicates the percentages, mean scores and discrepancies between pre-and post-test performance.

Out of the post-test findings, one out of twenty three learners obtained Band 5 , a competent user, ranging from 45 per cent to 52 per cent, while one out of twenty three learners obtained Band 4, a satisfactory user, ranging from 37 per 
Table 2. The percentage, mean scoresand discrepancies between pre and post test performance.

\begin{tabular}{|c|c|c|c|c|c|}
\hline \multirow{2}{*}{ Pseudonym } & \multicolumn{4}{|c|}{ Result } & \multirow{2}{*}{$\begin{array}{l}\text { Differences of } \\
\text { results }\end{array}$} \\
\hline & Pre-Test & Grade (Band) & Post-Test & Grade (Band) & \\
\hline Allysha & 13 & 1 & 22 & 2 & +9 \\
\hline Amalyn & 26 & 2 & 29 & 3 & +3 \\
\hline Brenda & 5 & 1 & 7 & 1 & +2 \\
\hline Calvin & 24 & 2 & 30 & 3 & +6 \\
\hline Caroline & 26 & 2 & 30 & 3 & +4 \\
\hline Dayangku & 5 & 1 & 5 & 1 & 0 \\
\hline Gwendolyne & 39 & 4 & 46 & 5 & +7 \\
\hline Hafizul & 23 & 2 & 29 & 3 & +6 \\
\hline Ivy & 20 & 1 & 24 & 2 & +4 \\
\hline Joshua & 20 & 1 & 20 & 1 & 0 \\
\hline Maxwell & 12 & 1 & 12 & 1 & 0 \\
\hline Myronne & 21 & 2 & 25 & 2 & +4 \\
\hline Aina & 22 & 2 & 29 & 3 & +7 \\
\hline Asyraaf & 23 & 2 & 29 & 3 & +6 \\
\hline Nur'ain & 23 & 2 & 31 & 3 & +8 \\
\hline Nurazwarhani & 23 & 2 & 27 & 2 & +4 \\
\hline Azreen & 10 & 1 & 21 & 2 & +11 \\
\hline Farhana & 15 & 1 & 23 & 2 & +8 \\
\hline Masdiana & 17 & 1 & 21 & 2 & +4 \\
\hline Slyvestine & 30 & 3 & 39 & 4 & +9 \\
\hline Suwandi & 24 & 2 & 24 & 2 & 0 \\
\hline Victor & 23 & 2 & 29 & 3 & +6 \\
\hline Wilnie & 16 & 1 & 18 & 1 & +2 \\
\hline Mean Score & 20.0 & 1 & 24.8 & 2 & +4.8 \\
\hline
\end{tabular}

cent to 44 per cent. The mean score for the overall post-test was $24.8 \%$, suggesting that the participants were restricted users, and that the participants had progressed from "very limited user" to "limited user." In contrast to the pre-test, both learners progressed by $4.8 \%$ on average. As Bowyer-Crane et al. (2017), Bowyer-Crane et al. (2017) and Safataj and Amiryousefi (2016) have argued, achieving good grades has demonstrated that learners have been able to grasp the questions or statements offered in the evaluation. It has also been found out that success in the assessment grade is a direct product of a high to optimum 
standard of understanding of learning. As a result, the increase in the performance of the post-test showed that the process-based writing approach helped the learner prepare and direct them through essay writing. As the outcome can also be changed, this matter has been listed for further study and recommendations.

\section{Issues and Challenges}

\subsection{The Teachers}

Some of the teachers are more familiar with the conventional teaching process. However, it does not work with those learners who have requested more fascinating methods of teaching so they are not inspired, which adds to their bad performance. According to Sultana (2016), a classroom would not be a good place to study if students were not inspired to learn. Therefore, instead of feeding the learners with a spoon, teachers should only become instructors and let the learners be autonomous while writing an essay using the $5 \mathrm{~W} 1 \mathrm{H}$ template. Further studies, however, aimed at creating more comprehensive and methodological techniques and guidelines for the use of a process-based writing methodology, in order to improve the abilities of learners in writing, in particular, an argumentative essay. The effectiveness of this method depends on how well the instructor is qualified to use this technique.

\subsection{The Learners'}

MUET syllabus was made according to the Common European Framework Reference for Languages (CEFR) to make sure it is on par with other international English Proficiency Test. Thus, the government took an initiative by stressing on the importance of MUET among the learners especially the Pre-university learners. Since 2014, the learners who wish to apply to public universities need MUET. The government also set a minimum MUET band requirement upon entering and graduating depending on their chosen courses (News Straits Time 2016). Writing paper could be difficult for the less proficient learners and lack of general knowledge which always happened among the suburban school second language learners. Learners tend to merely list the points without relevant elaboration as they can't depend solely on their previous knowledge in writing the essay but they also need to read to gain more general knowledge. Apart from that, the learners tend to have difficulty in understanding the requirements of the essay question well. According to New Straits Times (2016), "the tendency of not to fulfil the requirements of the essay cause them to go off tangent when they write the essay which cost them to lose some of the marks." This statement can be supported by the analysis done by the Majlis Peperiksaan Malaysia (2018). MUET Session 3/2018 recorded $63.18 \%$ of the candidates managed to score band 3 for their writing paper (Majlis Peperiksaan Malaysia 2018). This is a worrying situation because, according to the analysis provided by Majlis Peperiksaan Malaysia (2018), the candidates were not able to provide good answers and were 
unable to elaborate on their ideas. Hence, the learners' should also have their own initiative to add on their knowledge by reading more related materials so that it can help them in their writing.

\section{Proposal}

\subsection{Organizing Writing Workshop}

Writing workshop can be carried out not necessarily in schools. For example, it can be done in the camp like English Camp that is often organized by the school where they collaborate with NGOs', Family Day and also any tournaments that require them to use English. The content of the workshop should include on the use of process-based approach in their writing activity. Active participation from various parties is needed to make sure the workshops are interesting and most importantly, beneficial for the learners.

\subsection{Organizing Writing Competition}

This competition can be held at schools or any organization to attract and encourage them in practicing their writing skills. The topic of the competition should be based on their interest and current issues which will indirectly encourage them to use their previous knowledge in writing. This kind of competition is suitable for everyone regardless their age. Competition with cash prizes will also attract their attention and interest which encourages and inspires boundless creativity among the participants.

\subsection{Organizing Hands on Workshop for Parents and Community}

The parents and community participation are crucial. They should prepare themselves with appropriate knowledge before they can educate and guide the young generation. The workshop can be held at school or during seminar and it has to be conducted by the teachers or others to encourage the participation from parents and also community.

\section{Conclusion}

Obviously, a good planning and collaboration from various people play an important role to help the learners to be a good writer. Teachers, on the other hand, need to work on and explore the approach that they chose for their writing class. Learners also need to give their full commitment towards the new approach and the results will show after a month or two if they consistently follow the instructions. Hence, process based writing approach can be employed as a beneficial teaching and learning aid to introduce, guide and support the learning of writing an argumentative essay.

\section{Conflicts of Interest}

The authors declare no conflicts of interest regarding the publication of this paper. 


\section{References}

Bowyer-Crane, C., Fricke, S., Schaefer, B., Lervåg, A., \& Hulme, C. (2017). Early Literacy and Comprehension Skills in Children Learning English as an Additional Language and Monolingual Children with Language Weaknesses. Reading and Writing, 30, 771-790. https://doi.org/10.1007/s11145-016-9699-8

Dick, B. (2015). Reflections on the SAGE Encyclopedia of Action Research and What It Says About Action Research and Its Methodologies. Action Research, 13, 431-444. https://doi.org/10.1177/1476750315573593

Forero, D. A., Lopez-Leon, S., González-Giraldo, Y., \& Bagos, P. G. (2019). Ten Simple Rules for Carrying Out and Writing Meta-Analyses. PLOS Computational Biology, 15, e1006922. https://doi.org/10.1371/journal.pcbi.1006922

Johnson, D., \& Johnson, R. (2020). What Is Cooperative Learning?-Cooperative Learning Institute. http://www.co-operation.org/what-is-cooperative-learning

Jones, S. (2015). Authenticity and Children's Engagement with Writing. Language and Literacy, 17, 63-82. https://doi.org/10.20360/G22C7I

Klimova, B. (2012). The Importance of Writing. Paripex-Indian Journal of Research, 2, 9-11. https://doi.org/10.15373/22501991/JAN2013/4

Laidlaw, M. (1992). Action Research: A Guide for Use on Initial Teacher Education Programmes. ActionResearch.Net.

Lewin, K. (1946). Action Research and Minority Problems. Journal of Social Issues, 2, 34-46.

https://spssi.onlinelibrary.wiley.com/doi/abs/10.1111/j.1540-4560.1946.tb02295.x

https://doi.org/10.1111/j.1540-4560.1946.tb02295.x

Majlis Peperiksaan Malaysia. (2018). Laporan Peperiksaan MUET. Selangor Darul Ehsan. Sasbadi Sdn Bhd.

https://www.mpm.edu.my/sumber/penerbitan/laporan-peperiksaan-stpm-dan-muet/2 $\underline{018}$ ? download=21:laporan-peperiksaan-muet \&start $=20$

New Straits Times (2016). Make MUET a Must for University Admission. http://www.nst.com.my/

Safataj, M., \& Amiryousefi, M. (2016). Effect of Homonymous Set of Words Instruction on Vocabulary Development and Retention of Young Female Elementary Learners in Iranian EFL Context through Metalinguistic Awareness. Theory and Practice in Language Studies, 6, 2092-2101. https://doi.org/10.17507/tpls.0611.05

Schneer, D. (2014). Rethinking the Argumentative Essay. TESOL Journal, 5, 619-653. https://doi.org/10.1002/tesj.123

Sheeba, S. (2018). Teaching Writing: Issues and Challenges.

Siddique, M., \& Singh, M. K. S. (2017). Role of Cooperative Learning in Enhancing Students' Writing Skills in Pakistani Colleges: A Review of Literature. Proceedings of The ICECRS, 1, 985-990. https://doi.org/10.21070/picecrs.v1i1.641

Sultana, S. (2016). Preference towards Modern Day Teaching and Traditional Teaching Aids among the Bangladeshi Tertiary Level Students.

http://dspace.bracu.ac.bd/xmlui/handle/10361/7639 